\title{
Demencia rápidamente progresiva por encefalitis límbica por anticuerpos LGl-1 y encefalopatía de Hashimoto. Presentación de dos casos y revisión de la literatura
}

\author{
Rapidly progressive dementia caused by limbic encephalitis \\ due to LGl-1 antibodies and hashimoto encephalopathy. \\ Report of two cases and literature review
}

Miguel Angel Nuñez Viejo, Ana Latorre Díez
Servicio de Medicina Interna. Complejo Hospitalario Universitario de Ourense

\section{RESUMEN}

Las demencias rápidamente progresivas (DRP) engloban un grupo muy heterogéneo de entidades caracterizadas por la aparición de trastornos cognitivos y conductuales relevantes que evolucionan en pocas semanas 0 meses. La triada clínica habitual consiste en pérdida de memoria, alteraciones psiquiátricas y crisis epilépticas. Aunque el síndrome de DRP engloba numerosos cuadros clínicos, es habitual pensar en un origen autoinmune paraneoplásico, infeccioso o asociado a enfermedades priónicas. Para su diagnóstico son necesarios estudios de imagen, el examen del líquido cefalorraquídeo y pruebas serológicas como la determinación de antígenos. Es importante establecer un diagnóstico diferencial precoz entre encefalopatías autoinmunes y demencias por trastornos neurodegenerativos, sobre todo en las de origen paraneoplásico, debido a que el tratamiento de la neoplasia es más efectivo en las fases tempranas de la enfermedad y puede evitar el daño neuronal irreversible. Presentamos dos casos de pacientes con deterioro cognitivo de pocos días de evolución debido a una encefalitis límbica no paraneoplásica y una encefalopatía de Hashimoto, causas poco habituales pero reversibles de demencia rápidamente progresiva.

Palabras clave: Demencia rápidamente progresiva. Encefalitis límbica. Anticuerpos antiLGl-1. Encefalopatía autoinmune. Encefalopatía de Hashimoto.

\section{INTRODUCCIÓN}

Las demencias rápidamente progresivas (DRP) comprenden un grupo de enfermedades caracterizadas por el desarrollo de trastornos cognitivos y de conducta que evolucionan en el curso de semanas a pocos meses ${ }^{1}$. La presentación clínica habitual consiste en pérdida de memoria, alteraciones psiquiátricas (incluidas alucinaciones), crisis epilépticas, ataxia, alteraciones del sueño, disautonomía, mioclonías y otros trastornos del movimiento ${ }^{1}$.

Las causas más importantes de DRP (tabla 1) incluyen las encefalopatías por priones, particularmente la enfermedad de Creutzfeldt-Jakob; encefalopatías autoinmunes como la encefalitis límbica (paraneoplásica o no paraneoplásica) y las encefalopatías que responden a corticosteroides; vasculitis; infecciones como la enfermedad de Whipple; neoplasias, particularmente el linfoma intravascular; causas toxicometabólicas y la seudodemencia asociada a depresión ${ }^{1}$. No obstante, en todo paciente con DRP debe descartarse el estado de mal epiléptico no convulsivo².

\section{ABSTRACT}

Rapidly progressive dementias (RPD) are a very heterogeneous group of diseases characterized by acute cognitive impairment and behavioral disorders in a few weeks or months. Clinically most of times consists of memory loss, psychiatric disorders and epilepsy. Although RPD can be part of multiple clinical conditions, most common causes include autoimmune diseases, infectious or prion diseases and rarely, as a manifestation of a paraneoplastic syndrome. Image studies, cerebral spinal fluid evaluation, and serologic tests such as antigen determination are the most useful in diagnosing a neurological paraneoplastic syndrome. It's very interesting an early diagnosis because the treatment is more effective in the early stages of illnes and can prevent irreversible neuronal damage. We present two cases of patients with rapidly cognitive impairmen due to limbic encephalitis and Hashimoto encephalopathy, rare but reversible causes of dementia.

Keywords: rapidly progressive dementia, limbic encephalitis, LGI-1 antibodies, autoimmune encephalopathy, Hashimoto encephalopathy, antithyroid antibodies, paraneoplastic syndrome, antineuronal antibodies.

Conviene también recordar que las demencias neurodegenerativas clásicas, como la enfermedad de Alzheimer, la demencia frontotemporal, la demencia con cuerpos de Lewy, la degeneración corticobasal y la parálisis supranuclear progresiva, pueden en ocasiones tener un comportamiento rápidamente progresivo y evolucionar en el curso de uno a dos años ${ }^{3-5}$, aunque es muy raro por lo general. Las que con mayor frecuencia pueden progresar de esta forma son la demencia con cuerpos de Lewy, la degeneración corticobasal y, en algunos casos, la demencia frontotemporal. La enfermedad de Alzheimer con angiopatía amiloide cerebral también puede evolucionar en forma subaguda ${ }^{5}$.

El diagnóstico y estudio de pacientes con DRP debe incluir exámenes de laboratorio a fin de descartar causas metabólicas o nutricionales como el déficit de vitamina B12, un electroencefalograma (EEG), una resonancia magnética (RM) cerebral, examen del líquido cefalorraquídeo (LCR) y la búsqueda de autoanticuerpos (tabla 2). 
Tabla 1. Demencias rápidamente progresivas

\begin{tabular}{|c|c|}
\hline \multicolumn{2}{|c|}{ Enfermedades neurodegenerativas } \\
\hline \multicolumn{2}{|c|}{$\begin{array}{l}\text { - Enfermedades priónicas (enfermedad de } \\
\text { Creutzfeldt-Jakob, Kuru, otras...) } \\
\text { - Demencias neurodegenerativas clásicas con curso } \\
\text { atípico (muy poco frec.), sobre todo la demencia con } \\
\text { cuerpos de Lewy y la degeneración corticobasal }\end{array}$} \\
\hline \multicolumn{2}{|c|}{ Infecciones del sistema nervioso central } \\
\hline $\begin{array}{l}\text { Infecciones víricas } \\
\text { - Encefalitis convencionales } \\
\text { - Demencia asociada al VIH } \\
\text { - Leucoencefalopatía } \\
\text { multifocal progresiva } \\
\text { - Panencefalitis esclerosante } \\
\text { subaguda }\end{array}$ & $\begin{array}{l}\text { Infecciones bacterianas } \\
\text { - Sífilis } \\
\text { - Brucelosis } \\
\text { - Tuberculosis } \\
\text { - Enfermedad de Lyme } \\
\text { - Enfermedad de Whipple }\end{array}$ \\
\hline \multicolumn{2}{|l|}{$\begin{array}{l}\text { Otras } \\
\text { - Infecciones fúngicas } \\
\text { - Parasitosis }\end{array}$} \\
\hline \multicolumn{2}{|c|}{ Encefalopatías autoinmunes, inflamatorias y granulomatosis } \\
\hline \multicolumn{2}{|c|}{$\begin{array}{l}\text { Encefalitis límbica (asociadas a anticuerpos antineuronales) } \\
\text { - Paraneoplásica } \\
\text { - No paraneoplásica } \\
\text { Encefalopatías que responden a corticoides } \\
\text { - Asociada a anticuerpos antitiroideos (encefalitis de Hashimoto) } \\
\text { - Conectivopatías: síndrome de Sjögren, lupus eritematoso sistémico } \\
\text { - Sarcoidosis y otras granulomatosis } \\
\text { - Encefalopatías sin anticuerpos asociados } \\
\text { Vasculopatías inflamatorias } \\
\text { - Vasculitis aislada del sistema nervioso y vasculitis sistémicas } \\
\text { - Síndrome antifosfolipídico } \\
\text { - Síndrome de Susac } \\
\text { Formas cognitivas de Esclerosis Múltiple }\end{array}$} \\
\hline \multicolumn{2}{|c|}{ Enfermedades cerebrovasculares } \\
\hline \multicolumn{2}{|c|}{$\begin{array}{l}\text { - Infartos cerebrales múltiples y estratégicos } \\
\text { - Trombosis de senos venosos } \\
\text { - Fístulas durales y otras malformaciones vasculares }\end{array}$} \\
\hline \multicolumn{2}{|c|}{ Neoplasias } \\
\hline \multicolumn{2}{|c|}{$\begin{array}{l}\text { - Neoplasias primarias (linfoma intravascular, linfoma } \\
\text { primario del SNC, gliomatosis cerebri...) } \\
\text { - Metástasis y carcinomatosis meníngea } \\
\text { - Síndromes paraneoplásicos no autoinmunes }\end{array}$} \\
\hline \multicolumn{2}{|c|}{ Hidrocefalias } \\
\hline \multicolumn{2}{|c|}{$\begin{array}{l}\text { - Hidrocefalias idiopáticas (síndrome de Hacking- } \\
\text { Adams o hidrocefalia normotensiva) } \\
\text { - Hidrocefalias secundarias }\end{array}$} \\
\hline \multicolumn{2}{|c|}{ Intoxicaciones } \\
\hline \multicolumn{2}{|l|}{$\begin{array}{l}\text { - Tóxicos ambientales } \\
\text { - Drogas } \\
\text { - Fármacos }\end{array}$} \\
\hline \multicolumn{2}{|c|}{ Cuadros metabólicos, endocrinos y carenciales } \\
\hline \multicolumn{2}{|c|}{$\begin{array}{l}\text { - Déficit de vitamina B1, vitamina B12, vitamina E, niacina y folato } \\
\text { - Insuficiencia renal, hepática, cardiaca y respiratoria } \\
\text { - Alteraciones hidroelectrolíticas: hipercalcemia, hiponatremia } \\
\text { - Enfermedades endocrinas (tiroides -tirotoxicosis, } \\
\text { mixedema-, paratiroides, suprarrenales) } \\
\text { - Otras: enfermedad de Wilson, Porfiria }\end{array}$} \\
\hline \multicolumn{2}{|l|}{ Epilepsia } \\
\hline Enfermedades psiquiátricas & \\
\hline
\end{tabular}

Tabla 2. Estudios complementarios de interés en el diagnóstico de las demencias rápidamente progresivas

\begin{tabular}{|l|}
\hline Laboratorio de rutina \\
\hline - Hemograma, coagulación y VSG \\
- Bioquímica básica con pruebas de función \\
hepática y perfil férrico y tiroideo (TSH) \\
- Calcio \\
- Ácido fólico y vitamina B12 \\
- ECA \\
\hline Serología \\
\hline - Sífilis \\
- VIH \\
\hline Pruebas reumatológicas \\
\hline - ANA \\
- Anti-Ro y anti-La \\
\hline Autoanticuerpos \\
\hline - Intracelulares (o paraneoplásicos clásicos): Hu, \\
Yo, Ri, Ma, Ma2, CV2/CRMP-5 y amfifisina \\
- Antígenos de membrana neuronal: contra los canales \\
de potasio voltaje-dependientes (anti-LGl1), contra el \\
receptor de glutamato o N-metil-D-aspartato (anti- \\
RNMDA), contra el neurópilo del hipocampo \\
- Antitiroideos: contra la peroxidasa tiroidea (anti-TPO), \\
anti-tiroglobulina (TG) y anti-receptor de TSH (TSI) \\
\hline Otras pruebas \\
\hline - EEG \\
- RM cerebral con gadolinio (con secuencia FLAIR y difusión) \\
- En algunos casos: \\
- TC tórax, abdomen y pelvis \\
- Ecografía de pelvis o testicular \\
- PET/TC con FDG \\
- Biopsia periférica (glándula lagrimal o salival) \\
\hline Examen de LCR \\
\hline - Citología, glucosa, proteínas, bandas oligoclonales, VDRL \\
- PCR para enfermedad de Whipple \\
- Proteína 14-3-3 o enolasa específica \\
- Antígeno para criptococo \\
- PCR herpesvirus y otros \\
- Cultivo: bacterias, hongos y Mycobacterium tuberculosis \\
\hline Biopsia de cerebro y leptomeninges \\
\hline
\end{tabular}

HIV, virus de la inmunodeficiencia humana; ANA, anticuerpos antinucleares; PCR, reacción en cadena de la polimerasa.

En ocasiones, la biopsia cerebral puede ser útili ${ }^{6}$, pero no se recomienda su realización si la sospecha diagnóstica es una enfermedad por priones. Tiene una sensibilidad muy variable y su principal indicación es la sospecha de una enfermedad potencialmente tratable, en presencia de una lesión bien definida y accesible cuya localización no entrañe el riesgo de un daño neurológico mayor derivado del propio procedimiento.

Si tras haber realizado todos los estudios necesarios y excluido el origen infeccioso, no puede establecerse la causa de una DRP, está justificado el tratamiento empírico con dosis altas de corticoides en pacientes que sufran un rápido deterioro ${ }^{1,7}$. 


\section{CASO CLÍNICO 1}

Se trata de un paciente varón de 56 años con antecedentes de bebedor, exfumador, obesidad, hipertensión arterial, diabetes mellitus tipo 2 y dislipemia, que ingresó en mayo de 2012 en el servicio de Medicina Interna por deterioro cognitivo de aproximadamente dos semanas de evolución, con episodios de desconexión del medio y desorientación temporo-espacial, alucinaciones visuales y movimientos clónicos de extremidades superiores de predominio nocturno, estos últimos ya desde unos meses antes, motivo por el que había consultado con un neurólogo privado sin encontrarse patología alguna y que habían mejorado parcialmente con la administración de lamotrigina. En ningún momento presentó generalización de las crisis, periodo postcrítico ni relajación de esfínteres, pero sí cefalea acompañante de forma ocasional. La familia refería además episodios de sudoración, insomnio, apneas e hipersomnia diurna. Negaban pérdida de peso o síndrome constitucional asociado. Como último dato, el enfermo comentaba un antecedente de herpes zoster cutáneo intercostal un mes antes del ingreso, resuelto tras completar tratamiento con brivudina.

En el examen físico no hubo hallazgos destacables, salvo hipertrofia parotídea como estigma de su enolismo crónico, y a nivel neurológico un examen cognitivo deteriorado (MMSE 28/30) a expensas de errores en la memoria inmediata y en el cálculo. Tanto a nivel motor y sensitivo, como en la coordinación y la marcha no se encontró alteración alguna.

Con la clínica sugerida se llevaron a cabo pruebas complementarias encaminadas al diagnóstico diferencial planteado: infeccioso (sobre todo encefalitis por herpes dado el antecedente mencionado); enfermedad por priones; tóxico, Wernicke; vascular; paraneoplásico y, por último; autoinmune, encefalitis límbica.

En los estudios complementarios destacó hiponatremia (Na+ 129 $\mathrm{mmol} / \mathrm{L})$, ya presente en los controles analíticos del último mes, y una VSG ligeramente elevada ( $30 \mathrm{~mm} / 1 \mathrm{~h}$ ). En cuanto al examen del LCR, bioquímica, citología y ADA fueron normales, la proteína 14-33 negativa al igual que la detección de anticuerpos paraneoplásicos (Anti-Ma2, Anti-Ma, Anti-Amfifisina, Anti-CV2/CRMP5, Anti-RNMDA, Anti-Ri, Anti-Yo y Anti-Hu), pero la determinación de anticuerpos anti-canales de potasio voltaje-dependiente LGl-1 fue positiva a título alto: 92,3 pmol/L (normal < 10), al igual que en sangre $[663,60$ $\mathrm{pmol} / \mathrm{L}$ (normal < 100)]. El EEG mostró actividad epileptiforme a nivel frontal y en área temporal izquierda. En la RM cerebral se apreció una hiperintensidad en ambos lóbulos temporales (figura 1) y el PET/ TC reveló datos de hipermetabolismo al mismo nivel (figura 2). El SPECT cerebral encontró alteraciones de la perfusión cerebral de la corteza parietal bilateral, con disminución de la perfusión de la porción inferior del asta lateral del lóbulo temporal izquierdo, hallazgos sugestivos de proceso neurodegenerativo.

El resto de los estudios (hemograma, cortisol, calcio, bioquímica, tóxicos en orina, estudio inmunológico, marcadores tumorales, estudio de hipercoagulabilidad, estudio de anemia, coagulación, cultivo de orina y hemocultivo, cultivo de LCR, serologías, radiografía de tórax, ecografía pélvica y testicular, TC de tórax-abdomen-pelvis y $\mathrm{PET} / \mathrm{TC}$ corporal) fueron negativos.

Finalmente, ante el cuadro clínico sugestivo (deterioro cognitivo, alteraciones del comportamiento y crisis epilépticas) y los hallazgos descritos, unido a la ausencia de neoplasia en el estudio realizado y la presencia de anticuerpos LGI-1 tanto en sangre como en LCR, se concluyó el diagnóstico de encefalitis límbica por anticuerpos contra los canales de potasio voltaje-dependientes.
Figura 1. Corte transversal de RM cerebral que muestra un aumento de señal en región temporal profunda de hemisferio izquierdo y corteza temporal medial derecha, así como moderado engrosamiento cortical de la circunvolución parahipocámpica medial, datos compatibles con encefalitis límbica.

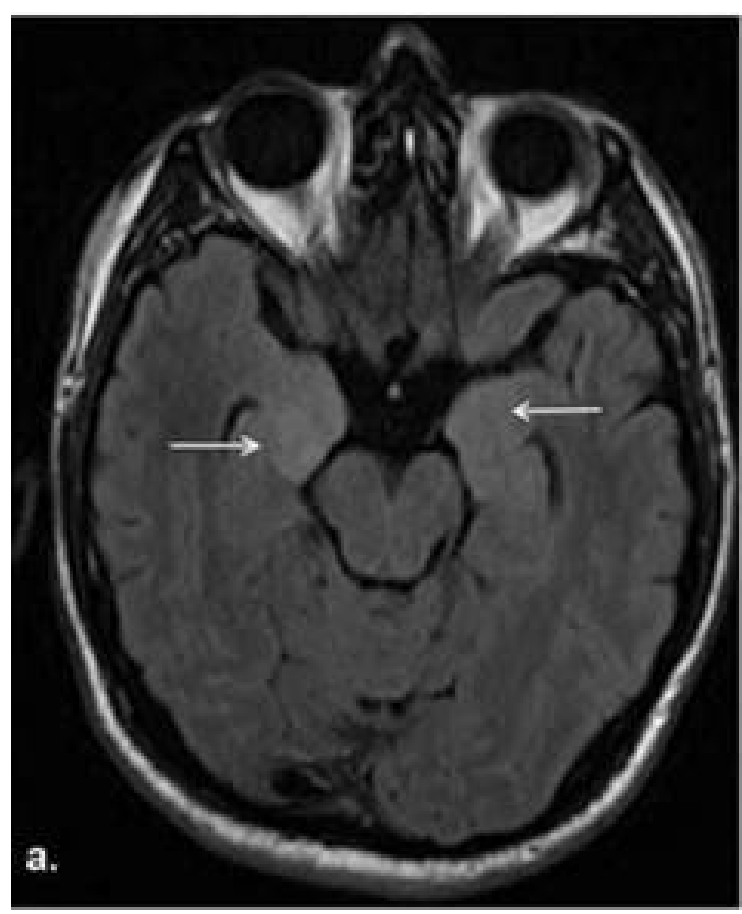

Figura 2. Imagen de estudio de PET-TC cerebral donde se objetiva un aumento focal de la captación de FDG en el lóbulo temporal izquierdo y asimetría en la captación a nivel ganglionar basal ipsilateral.
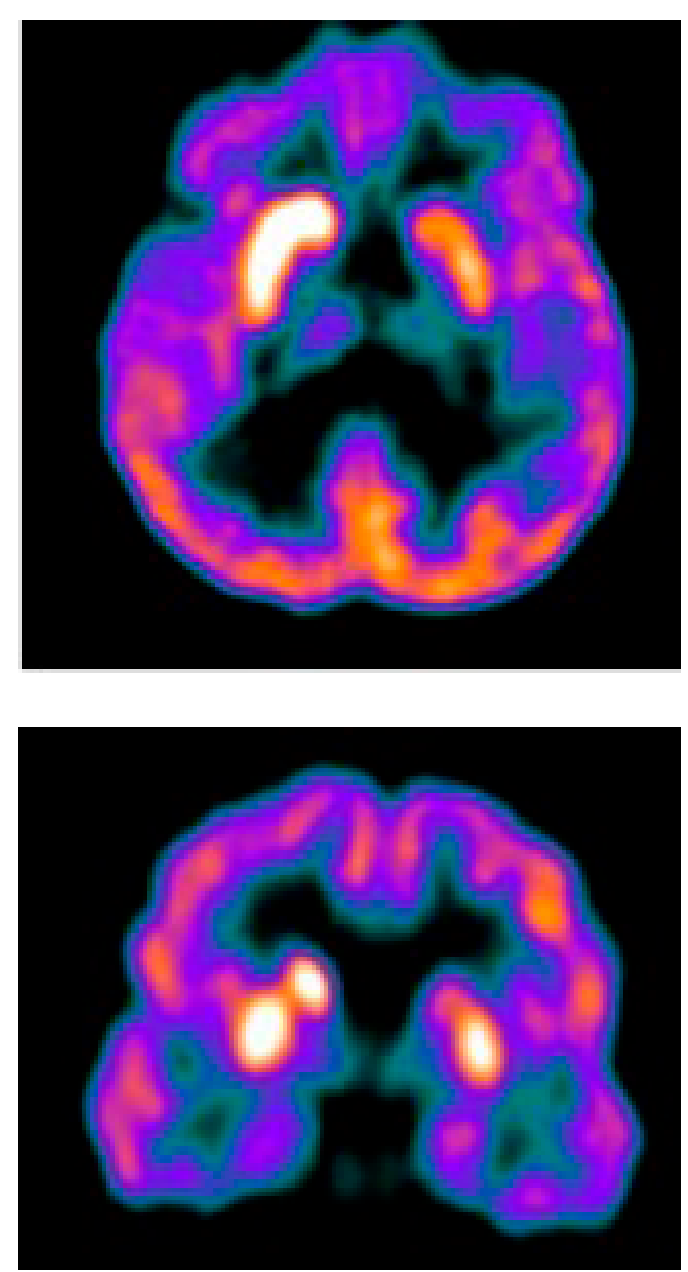
En cuanto a la evolución, desde el punto de vista neurológico a las pocas horas de su ingreso presentó cuadro de agitación psicomotriz con desorientación, comenzando 72 horas después con fiebre, alucinaciones visuales, desaturación y deterioro del nivel de conciencia que obligó a su traslado a la Unidad de Cuidados Intensivos. Ante el resultado positivo de anticuerpos anti-LGl1 obtenido en el estudio del LCR se inició tratamiento con corticoides (prednisona), micofenolato sódico y bolus de inmunoglobulinas, con buena respuesta que permitió en pocas semanas el alta hospitalaria. Durante su estancia, en todo momento mantuvo cifras bajas de sodio alcanzando valores mínimos de $117 \mathrm{mEq}$, natremia que sólo pudo corregirse con la administración de tolvaptan. En el seguimiento posterior en la consulta de Medicina Interna se ha comprobado mejoría neurológica progresiva hasta tal punto que ha recuperado la memoria, no ha tenido nuevos episodios de alucinaciones visuales ni trastornos del sueño y no existe evidencia alguna de deterioro cognitivo.

\section{CASO CLÍNICO 2}

Mujer de 81 años con antecedentes de hipertensión arterial e hipertensión pulmonar leve, diagnosticada en 2014 de un carcinoma de mama con afectación metastásica hepática y ósea, que había progresado a diferentes líneas de quimioterapia, estando en el momento del ingreso en tratamiento con letrozol y lapatinib. Previamente, en mayo de 2017, había recibido radioterapia antiálgica sobre las lesiones óseas por un cuadro de dolor para el que estaba recibiendo opioides.

Ingresó en junio de 2017 en Medicina Interna procedente del Servicio de Urgencias por alteración conductual de aproximadamente dos semanas de evolución, junto con episodios de agitación nocturna, desorientación, agresividad y negativa a la ingesta. Previo al ingreso, la enferma vivía sola, no tenía antecedentes de deterioro cognitivo y era totalmente independiente para las actividades básicas.

En el examen físico no había datos relevantes salvo a nivel neurológico, donde destacaba desorientación temporo-espacial, deterioro cognitivo (MMSE 24/30) y bradipsiquia con alteración del curso del pensamiento y lenguaje incoherente, incontinencia de esfínteres y agitación psicomotriz con episodios de agresividad tanto física como verbal.

Con la clínica sugerida se decidió ingreso para estudio y se solicitaron pruebas complementarias encaminadas al diagnóstico diferencial planteado: neoplásico, afectación metastásica cerebral, carcinomatosis meníngea; tóxico, neurotoxicidad inducida por opioides; metabólico, hipercalcemia tumoral, hiponatremia, encefalopatía hepática; infeccioso; vascular y, por último; autoinmune, encefalitis límbica paraneoplásica.

En lo referente a los estudios complementarios tanto bioquímica como hemograma no mostraban alteraciones y los valores de vitamina B12 y ácido fólico, al igual que el perfil tiroideo, también eran normales. Se descartaron infecciones intercurrentes y se amplió el estudio con serologías víricas, incluyendo sífilis y VIH, todas negativas. Sin embargo, en el estudio inmunológico en plasma se encontraron los siguientes hallazgos: ANA positivos (1/80), Ac antitiroperoxidasa (TPO) $219 \mathrm{Ul} / \mathrm{mL}$ (normal 0 - $35 \mathrm{Ul} / \mathrm{mL}$ ) y Ac antitiroglobulina (TG) $417 \mathrm{Ul} / \mathrm{mL}$ (normal < $50 \mathrm{Ul} / \mathrm{mL}$ ), con anticuerpos anti-receptor de TSH (TSI o TR) normales. Se completó el estudio con un EEG, que mostró una moderada desorganización y lentificación global del trazado, con brotes lentos difusos intermitentes de moderada frecuencia, y un TC craneal y una RM cerebral, que no mostraron alteraciones, descartándose así la afectación metastásica cerebral y meníngea. En el análisis del LCR también se confirmó la positividad de anti-TPO y anti-TG y se objetivó un leve aumento de proteínas, siendo negativo el resto del examen bioquímico y microbiológico, incluídas proteína 14-3-3 y detección de anticuerpos paraneoplásicos.

Ante el cuadro clínico descrito (deterioro cognitivo, alteración del comportamiento), la ausencia de afectación neoplásica del SNC y la presencia de anticuerpos antitiroideos en sangre y LCR, se estableció el diagnóstico de encefalopatía de Hashimoto. Esto, unido al rápido deterioro neurológico con disminución del nivel de consciencia que experimentó la enferma, obligó al tratamiento precoz con altas dosis de corticoides, con mejoría sorprendente en las primeras 72 horas de tratamiento. La evolución fue favorable y la enferma fue dada de alta una semana después. Por parte de Oncología Médica se descartó continuar tratamiento citotóxico, de forma que fue derivada a la Unidad de Cuidados Paliativos para seguimiento ambulatorio en consulta.

\section{DISCUSIÓN}

\section{Encefalitis límbica}

Las enfermedades autoinmunes asociadas a la aparición de autoanticuerpos específicos son la causa más frecuente de DRP potencialmente tratable ${ }^{2}$. Entre ellas se encuentra la encefalitis límbica, entidad poco frecuente y de difícil diagnóstico que se caracteriza clínicamente por una triada consistente en deterioro cognitivo, crisis epilépticas y manifestaciones psiquiátricas ${ }^{7-9}$, habitualmente de inicio subagudo -en días a semanas-, aunque en algunos casos pueden instaurarse de forma brusca. En personas adultas, las crisis epilépticas tienen su origen en el lóbulo temporal ${ }^{10}$ y las manifestaciones psiquiátricas incluyen una gran variedad de alteraciones, como cambios en la personalidad y estado de ánimo, depresión, psicosis, alucinaciones y deterioro de la memoria a corto plazo. Por regla general, la atención está conservada, dato clínico que suele ser de utilidad para diferenciarla de los síndromes confusionales ${ }^{8-10}$.

La causa de la encefalitis límbica permaneció sin explicación hasta la identificación de anticuerpos contra antígenos presentes en neuronas y células tumorales en los pacientes afectados, hallazgo que confirmó la teoría de que obedece a una causa inmune. Así, la encefalitis límbica autoinmune se debe a la presencia de autoanticuerpos y pueden detectarse hasta en el $80 \%$ de los enfermos ${ }^{11,12}$. Existen dos grandes grupos: aquellas que ocurren como una manifestación paraneoplásica, y las no paraneoplásicas ${ }^{13}$.

En general, los síndromes paraneoplásicos se definen como manifestaciones en sitios remotos a neoplasias malignas 0 sus metástasis, no relacionadas con el crecimiento tumoral $^{14}$, infección, alteraciones metabólicas, cirugía o cualquiera otra forma de tratamiento oncológico. La frecuencia de los síndromes paraneoplásicos con sintomatología neurológica es menor a 0,5/100.000 casos por año, y las neoplasias más frecuentemente asociadas son el carcinoma pulmonar 
de células pequeñas (CPCP), el cáncer de testículo y el timo$\mathrm{ma}^{9,13}$, aunque es frecuente que la neoplasia no se detecte ${ }^{15,16}$. Dentro de los síndromes paraneoplásicos del sistema nervioso, los más frecuentes son el síndrome miasténico (Lambert-Eaton), que afecta al 3\% de los pacientes con cáncer de pulmón de células pequeñas; la miastenia grave, que se presenta en el $15 \%$ de los pacientes con timomas; y la neuropatía periférica desmielinizante, que se ha observado hasta en el $50 \%$ de los pacientes con una variante rara de plasmocitoma conocida como POEMS. Estos síndromes paraneoplásicos en el sistema nervioso central (SNC) tienen mayor incidencia en mujeres y en personas mayores de 50 años, y en su caso la sintomatología neurológica suele preceder casi siempre al diagnóstico tumoral.

Hay dos categorías de anticuerpos asociados con encefalitis límbica. Una incluye anticuerpos contra antígenos intracelulares y que sólo ocurre en el contexto de enfermedad paraneoplásica (también llamados anticuerpos paraneoplásicos clásicos). Dentro de este grupo los más importantes son el anticuerpo anti-Hu y el anti-CRMP-5, asociados con el CPCP, y el anticuerpo anti-Ma2, más relacionado con neoplasias testiculares ${ }^{11,12}$. El otro grupo de anticuerpos está dirigido contra antígenos de membrana y pueden o no estar asociados con una neoplasia oculta ${ }^{10}$. Un ejemplo importante son los anticuerpos contra los canales del potasio voltaje-dependientes, que se acompañan de neoplasias en el 20\% de los $\operatorname{casos}^{17,18}$, fundamentalmente CPCP y timomas. También existen anticuerpos dirigidos contra los receptores del glutamato o NMDA (N-metil-D-aspartato), que con frecuencia se asocian al teratoma de ovario en mujeres, en cuyo caso el cuadro clínico es complejo y se caracteriza por trastornos psiquiátricos graves, catatonía, discinesias orofaciales, hipoventilación y disautonomía.

Los estudios analíticos rutinarios suelen ser normales, pero en el caso de la encefalitis límbica asociada a anticuerpos contra los canales de potasio suele observarse hiponatremia con relativa frecuencia. La RM cerebral puede mostrar imágenes de utilidad para el diagnóstico hasta en el $70 \%$ de los enfermos. Típicamente se aprecia un aumento de señal en la porción medial de los lóbulos temporales y, en fases más avanzadas, atrofia del hipocampo y de la amígdala de forma bilatera ${ }^{19}$. El electroencefalograma es útil en los casos de presentación en forma de cuadro confusional o con alteración del nivel de conciencia. En cerca del $50 \%$ de los enfermos puede mostrar actividad epileptiforme temporal uni o bilateral, o hallazgos más inespecíficos, como enlentecimiento difuso o focal temporal19. El examen del LCR es útil de cara a descartar infecciones. Puede ser normal o mostrar un ligero aumento de proteínas y pleocitosis linfocitaria $(<30 \text { células })^{20}$. El electromiograma (EMG) también puede ser útil en algunos casos como en pacientes con anticuerpos contra los canales de potasio 0 el síndrome de Lambert-Eaton ${ }^{21}$. En el caso de pacientes con sintomatología neurológica típica de encefalitis límbica también se pueden apreciar alteraciones metabólicas a nivel del hipocampo en el estudio mediante FDG-PET/TC.
Esta técnica es una herramienta diagnóstica de gran valor, ya que permite la detección temprana y evalúa la actividad metabólica corporal, con lo que puede descartarse además la presencia de una neoplasia maligna oculta ${ }^{16}$.

Por tanto, el diagnóstico de una encefalitis límbica se basa fundamentalmente en el cuadro clínico, la RM cerebral, el EEG y los hallazgos en el LCR y se confirma con la determinación de autoanticuerpos en suero, LCR 0 ambos ${ }^{11,12}$. Sin embargo, la ausencia de anticuerpos no excluye el diagnóstico, así como su única presencia tampoco lo confirma, al no ser ésta la única condición necesaria.

Dado que estos síndromes pueden confundirse fácilmente con trastornos psiquiátricos, el diagnóstico y tratamiento tempranos son de suma importancia para evitar un daño neuronal irreversible. El tratamiento de la encefalitis límbica paraneoplásica requiere dos enfoques diferenciados. Por un lado, el tratamiento supresor de la respuesta inmune generada por el daño neurológico, y por otro el tratamiento de la neoplasia subyacente si existe, tratamiento que, con frecuencia, es el único efectivo. En cuanto al primero, cabe señalar que, mientras que las encefalitis relacionadas con antígenos intracelulares son principalmente mediadas por respuestas citotóxicas (linfocitos T) y responden poco al tratamiento, las encefalitis relacionadas con antígenos de membrana, como los canales de potasio voltaje-dependiente y los receptores del glutamato, parecen ser mediadas por anticuerpos y suelen mejorar con el tratamiento en un alto porcentaje $(60-80 \%)^{11,12}$.

Los tratamientos inmunosupresores incluyen ciclofosfamida, tacrolimus e incluso anticuerpos monoclonales, como el ritu$x$ imab $^{22}$, aunque también se puede recurrir a la administración de inmunoglobulinas intravenosas o la plasmaféresis. Las dosis altas de corticoides suelen mejorar los síntomas a corto plazo, pero aumentan el riesgo de psicosis. Muchos pacientes requieren tratamiento antiepiléptico permanen$\mathrm{te}^{22-23}$.

En cuanto a la encefalitis límbica por anticuerpos anti-canales de potasio se trata de una alteración del sistema autoinmune bien conocida y definida, aunque poco descrita en la literatura. La etiología más común es la autoinmune, aunque puede verse asociada a procesos neoplásicos ${ }^{24}$. De los casos descritos hasta ahora se concluye que suele afectar a la región medial de los lóbulos temporales, sobre todo el hipocampo, lo que en la clínica se correlaciona con cambios en el carácter, irritabilidad, ansiedad, depresión, alteraciones del comportamiento, desorientación, inversión del ritmo sueño-vigilia y alucinaciones, amnesia anterógrada, crisis parciales complejas, trastornos del movimiento hipo-hipercinético y disminución del nivel de conciencia ${ }^{24-26}$. Puede acompañarse de trastornos autonómicos y endocrinos -suele asociar hiponatremia hasta en el $15-20 \%$ de los casos paraneoplásicos, sobre todo por desarrollo de SIADH-. Como hallazgo analítico es común encontrar anticuerpos contra las neuronas del hipocampo que son anticuerpos anti-canales de potasio voltaje dependien- 
tes. Estos anticuerpos están dirigidos en realidad contra una proteína del complejo molecular llamada LGl-1 (leucine-rich

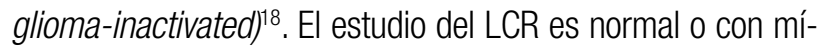
nimos cambios inflamatorios.

Las claves para el diagnóstico de esta entidad son clínicamente la alteración de la memoria y la aparición de crisis comiciales, y en los estudios complementarios valores de sodio repetidamente por debajo de la normalidad, engrosamiento a nivel de hipocampo izdo. en la RM y signos EEG de lesión temporal izquierda ${ }^{26}$. Esta entidad se puede asociar a enfermedad neoplásica en un $20 \%$ de los pacientes, por 10 que se debe hacer un estudio encaminado al despistaje de tumores concomitantes ${ }^{27}$. Como se ha mencionado antes, el tratamiento más aceptado en la actualidad incluye corticoides en combinación con inmunoglobulinas o plasmaféresis e inmunosupresores.

\section{Encefalopatía de Hashimoto}

La encefalitis de Hashimoto es una rara entidad en la que coexisten un deterioro cognitivo rápidamente progresivo (deterioro neurológico y funcional en un periodo inferior a dos años) y la presencia de anticuerpos antitiroideos -como los anti-peroxidasa tiroidea (TPO) y los anti-tiroglobulina (TG)- en títulos elevados, generalmente en ausencia de manifestaciones clínicas y de laboratorio de hipotiroidismo y sin que exista infección ni lesión estructural del sistema nervioso central $(\mathrm{SNC})^{28-32}$. También se conoce como encefalopatía que responde a esteroides asociada con anticuerpos antitiroideos (del inglés SREAT) y, de manera más general, como meningoencefalitis autoinmune no vasculítica.

Presenta una prevalencia de 2,1 casos por cada 100.000 habitantes, y afecta sobre todo a mujeres (con una proporción 5:1) de 50-60 años. La etiología es desconocida, aunque se considera que tiene un carácter autoinmune por la presencia de anticuerpos antitiroideos y la buena respuesta al tratamiento con esteroides ${ }^{32,33}$. En cuanto a la fisiopatología existen dos teorías: la primera, en la que los anticuerpos anti-peroxidasa tiroidea (TPO) además de encontrarse elevados en suero, también presentan niveles altos en líquido cefalorraquídeo (LCR), lo que iniciaría la cascada inflamatoria al unirse a los astrocitos y alteraría la función del SNC ${ }^{34}$; y la segunda, que defiende la existencia de anticuerpos contra antígenos del endotelio vascular cerebral, lo que conllevaría un daño neuronal.

Aunque los síntomas son muy variados, se describen dos formas de presentación ${ }^{34,35}$ : la primera y más típica, de tipo vasculítico o stroke-like, consiste en un deterioro cognitivo insidioso, fluctuante y con disminución del nivel de consciencia y en la que hasta el $80 \%$ de los pacientes presentan afasia transitoria, por lo que puede confundirse con un accidente cerebrovascular; y la segunda, que se comporta como una encefalopatía rápidamente progresiva con deterioro cognitivo, ataxia, mioclonías, crisis epilépticas, cefalea y manifestaciones psiquiátricas.
La determinación de anticuerpos antitiroideos (sobre todo anti-TPO y anti-TG) es esencial para el diagnóstico de la encefalitis de Hashimoto. No obstante, no está clara la relación entre la severidad de los síntomas neurológicos y la concentración sanguínea de anticuerpos. No se consideran un hallazgo específico de esta entidad, pues pueden estar elevados hasta en el $20 \%$ de la población general sana. También pueden estar elevados en LCR, pero no está clara la especificidad ni sensibilidad de su determinación. En el estudio de LCR lo habitual es encontrar una leve elevación de proteínas, raros los niveles mayores de $100 \mathrm{mg} / \mathrm{dL}$, y una mínima pleocitosis con predominio de linfocitos. En algunos casos se ha descrito elevación de la proteína 14-3-3, haIlazgo típicamente asociado a la enfermedad de Creutzfeldt$J \mathrm{k} o b^{36} \mathrm{y}$ del que se desconoce su significado patológico en esta entidad. En cuanto a los niveles de hormonas tiroideas lo habitual es que no se encuentren alterados, pero en un 23-35\% de los pacientes puede existir un hipotiroidismo subclínico y en torno al $7 \%$ tienen hipertiroidismo.

La RM cerebral es habitualmente normal, aunque en ocasiones pueden hallarse cambios en las sustancia blanca subcortical 0 aumento de señal a nivel menínge ${ }^{37}$. EI LCR puede mostrar un patrón inflamatorio inespecífico. En sangre se describe con frecuencia una elevación de VSG y de transaminasas. El EEG suele ser anormal y muestra enlentecimiento uni o bilateral ${ }^{38}$.

El diagnóstico es de exclusión, pues debido a la baja prevalencia no existen criterios definidos al respecto. No obstante, de forma general se acepta el mismo cuando el paciente presenta deterioro neurológico rápidamente progresivo, anticuerpos antitiroideos positivos a título elevado, no existe otra causa que justifique la clínica y se objetiva una respuesta considerable al tratamiento con corticoides ${ }^{34,35,38}$. El diagnóstico diferencial debe hacerse con la enfermedad de Creutzfeldt-Jakob (ECJ), la encefalitis límbica paraneoplásica, las vasculitis y las enfermedades psiquiátricas.

El tratamiento precoz mejora el pronóstico, de ahí la importancia de sospechar la enfermedad. Los corticoides a altas dosis son los fármacos de primera línea y la respuesta clínica favorable apoya el diagnóstico. La mayoría de los pacientes presentan mejoría a las pocas semanas, aunque a veces la respuesta es sorprendente ya con las primeras dosis. En aproximadamente la mitad de los casos se puede llegar a suspender el tratamiento, pero con frecuencia se describen recaídas que obligan a realizar un tratamiento a largo plazo y recurrir al uso de inmunosupresores como la azatioprina, el metotrexato o el micofenolato de mofetilo a fin de reducir los requerimientos de esteroides ${ }^{39}$, mientras que en casos refractarios suele recurrirse a la plasmaféresis ${ }^{36,40}$. La suspensión definitiva del tratamiento puede considerarse en enfermos que se mantengan estables durante al menos un año, siendo necesario su seguimiento posterior por la posibilidad de que desarrollen hipotiroidismo. 


\section{BIBLIOGRAFÍA}

1. Geschwind MD, Shu H, Haman A, et al. Rapidly Progressive Dementia. Ann Neurol 2008; 64:97-108.

2. Kaplan PW. The clinical features, diagnosis, and prognosis of nonconvulsive status epilepticus. Neurologist 2005;11:348-361.

3. Roberson ED, Hesse JH, Rose KD, et al. Frontotemporal dementia progresses to death faster than Alzheimer disease. Neurology 2005;65:719-725.

4. Rascovsky K, Salmon DP, Lipton AM, et al. Rate of progression differs in frontotemporal dementia and Alzheimer disease. Neurology 2005;65:397-403.

5. Lopez 0, Claassen D, Boller F. Alzheimer's disease, cerebral amyloid angiopathy, and dementia of acute onset. Aging (Milano)1991;3:171-175.

6. Josephson SA, Papanastassiou AM, Berger MS, et al. The diagnostic utility of brain biopsy procedures in patients with rapidly deteriorating neurological conditions or dementia. J Neurosurg 2007;106:72-75.

7. Vernino S, Geschwind MD, Boeve B. Autoimmune encephalopathies. Neurologist 2007;13:140-147

8. Tuzun E, Dalmau J. Limbic encephalitis and variants: classification, diagnosis and treatment. Neurologist 2007;13:261-271.

9. Gultekin SH, Rosenfeld MR, Voltz R, et al. Paraneoplastic limbic encephalitis: neurological symptoms, immunological findings and tumour association in 50 patients. Brain 2000;123:1481-1494.

10. Dropcho EJ. Update on paraneoplastic syndromes. Curr Opin Neurol 2005;18:331336.

11. Graus F, Saiz A. Encefalitis límbica: un síndrome probablemente infradiagnosticado. Neurologia 2005;20(1):24-30.

12. Dalmau J, Bataller L. Encefalitis límbica: Ios nuevos antígenos de membrana y propuesta de una clasificación clínicoinmunológica con implicaciones terapéuticas. Neurología 2007:22(8):526-537.

13. Rosenfeld MR, Dalmau J. Update on paraneoplastic neurologic disorders. Oncologist 2010;15(6):603-617.

14. Ramos Rivas M, Rojas Velasco G, Acuña Hidalgo R, et al. Encefalitis límbica paraneoplásica: una entidad de difícil diagnóstico. Rev Neurol 2009;48:311-316.

15. Ances BM, Vitaliani R, Taylor RA, et al. Treatment-responsive limbic encephalitis identified by neutrophil antibodies: MRI and PET correlates. Brain 2005;128:17641777.

16. Troester F, Weske G, Schlaudraff E, et al. Image of the month. FDG-PET in paraneoplastic limbic encephalitis. Eur J Nucl Med Mol Imaging. 2009;36:539.

17. Vincent A, Buckley C, Lang B, Irani S. Clinical spectrum of voltage-gated potassium channel autoimmunity. Neurology 2009;72:99.

18. Lai M, Huijbers MG, Lancaster E, et al. Investigation of LGl-1 as the antigen in limbic encephalitis previously attributed to potassium channels: a case series. Lancet Neurol 2010;9(8):776-785.

19. Lawn ND, Westmoreland BF, Kiely MJ, et al. Clinical, magnetic resonance imaging, and electroencephalographic findings in paraneoplastic limbic encephalitis. Mayo Clin Proc 2003;78:1363-1368.

20. Jarius $S$, Hoffmann $L$, Clover $L$, et al. CSF findings in patients with voltage gated potassium channel antibody associated limbic encephalitis. J Neurol Sci 2008;268:74-77.
21. Merchut MP. Management of voltage-gated potassium channel antibody disorders. Neurol Clin 2010; 28(4):941-959.

22. Shams'ili S, de Beukelaar J, Gratama JW, et al. An uncontrolled trial of rituximab for antibody associated paraneoplastic neurological syndromes. J Neurol 2006;253:16-20.

23. Vernino S, O'Neill BP, Marks RS, et al. Immunomodulatory treatment trial for paraneoplastic neurological disorders. Neuro-oncol 2004;6:55-62.

24. Brierley JB, Corsellis JA, Hierons R, Nevin S. Subacute encephalitis of later adult life. Mainly affecting the limbic areas. Brain 1960;83:357-368.

25. Soler B, Godoy J, Mellado P. Encefalitis límbica por anticuerpos anticanales de potasio dependientes de voltaje. Caso clínico. Rev Med Chile 2009;137:675-679.

26. Schott JM. Limbic encephalitis: a clinician's guide. Practical Neurology 2006;6:143-153

27. McKeon A. Autoimmune Encephalopathies and Dementias. Continuum: Lifelong Learning in Neurology 2016;22(2, Dementia):538-558.

28. Shaw PJ, Walls TJ, Newman PK, et al. Hashimoto's encephalopathy: a steroidresponsive disorder associated with high anti- thyroid antibody titers-report of 5 cases. Neurology 1991;41:228-233.

29. Castillo P, Woodruff B, Caselli R, et al. Steroid-responsive encephalopathy associated with autoimmune thyroiditis. Arch Neurol 2006;63:197-202.

30. Chong JY, Rowland LP, Utiger RD. Hashimoto encephalopathy: syndrome or myth? Arch Neurol 2003;60:164-171.

31. Chong JY, Rowland LP. What's in a NAIM? Hashimoto encephalopathy, steroid-responsive encepha- lopathy associated with autoimmune thyroiditis, or nonvasculitic autoimmune meningoencephalitis? Arch Neurol 2006;63:175-176.

32. Pinedo Torres I, Paz Ibarra J. Current knowledge on Hashimoto's encephalopathy: a literature review. Medwave 2018;18(06):e7298.

33. Sadan 0, Seyman E, Ash E, et al. Adult-onset temporal lobe epilepsy, cognitive decline, multi-antiepileptic drug hypersensitivity, and Hashimoto's encephalopathy: Two case studies. Epilepsy Behav Case Rep 2013;1:132-135.

34. Zhou J, Xu B, Lopes J, et al. Hashimoto encephalopathy: literature review. Acta Neurol Scand 2016:135(3):285-290.

35. Montagna G, Imperiali M, Agazzi P, et al. Hashimoto's encephalopathy: A rare proteiform disorder. Autoimmun Rev 2016;15(5):466-76.

36. Vander T, Hallevy C, Alsaed I, et al. 14-3-3 protein in the CSF of a patient with Hashimoto's encephalopathy. J Neurol. 2004;251(10):1273.

37. Bohnen NI, Parnell KJ, Harper CM. Reversible MRI findings in a patient with Hashimoto's encephalopathy. Neurology 1997:49:246-247.

38. Kothbauer-Margreiter I, Sturzenegger M, Komor J, et al. Encephalopathy associated with Hashimoto thyroiditis: diagnosis and treatment. J Neurol 1996;243:585-593.

39. Hussain NS, Rumbaugh J, Kerr D, et al. Effects of prednisone and plasma exchange on cognitive impairment in Hashimoto encephalopathy. Neurology 2005;64:165166

40. Lee S, Donlon S, Caplan J. Steroid Responsive Encephalopathy Associated with Autoimmune Thyroiditis (SREAT) or Hashimoto's Encephalopathy: A Case and Review. Psychosomatics 2011;52(2):99-108 